American Journal of Pharmaceutical Education 2019; 83 (4) Article 6622.

\title{
RESEARCH
}

\section{Using Team-Based Learning to Train Student Pharmacists to Perform Tuberculin Skin Testing}

\author{
Kimberly C. McKeirnan, PharmD, ${ }^{\mathrm{a}}$ Taylor G. Bertsch, PharmD, ${ }^{\mathrm{a}}$ Jennifer Arnold, PharmD, \\ Shannon G. Panther, PharmD \\ ${ }^{a}$ Washington State University College of Pharmacy, Spokane, Washington \\ ${ }^{\mathrm{b}}$ Washington State Pharmacy Association, Redmond, Washington \\ Submitted July 3, 2017; accepted August 22, 2017; published May 2019.
}

Objective. To evaluate the effectiveness of a team-based learning (TBL) model in training students to properly administer and interpret a tuberculin skin test (TST) in a laboratory course.

Method. Team-based learning was used to deliver TST training to all second-year student pharmacists $(n=120)$ in a patient care laboratory course. A 10-item TST Learning Opinion Survey was developed and administered to assess student pharmacists' self-perceived achievement of the class learning objectives, opinions about TBL learning experience, and interest in making TST a part of future practice.

Results. All 120 student pharmacists achieved competency standards during skills evaluation. One hundred thirteen out of 120 students completed the survey instrument. The majority of respondents either agreed or strongly agreed that TBL helped them meet the TST training learning objectives of: demonstrating administration proficiency; demonstrating interpretation competency; proper reporting and patient counseling with a positive test result; and identifying when a second TST was necessary. Additionally, a majority of respondents agreed or strongly agreed that the TBL model improved their knowledge of pre-laboratory material, aided their confidence in practicing TST placement, and improved their communication skills through peer work in a TBL environment.

Conclusion. Through this innovative model, student pharmacists met the TST learning objectives and developed knowledge and confidence. This activity can be replicated at other colleges, expanding the development of student pharmacists who are confident in their ability to provide TST services.

Keywords: tuberculin skin test; team-based learning; student pharmacist; patient care skills laboratory

\section{INTRODUCTION}

At the turn of the 20th century, one out of every seven people living in the United States and Europe died from tuberculosis (TB). ${ }^{1}$ In the 1940 s, medications were developed to treat TB, and the rates of illness declined. ${ }^{1}$ Unfortunately, the HIV epidemic in the 1980s led to an increased immunosuppressed population, resulting in a rise in mycobacterial diseases such as TB. ${ }^{2}$ History has shown that proper control measures, treatment, and ongoing identification of persons with latent and active TB illness are necessary for improved population health. ${ }^{1}$

The Centers for Disease Control and Prevention (CDC) recommends screening individuals considered to be at higher risk for either exposure to or transmission of TB infections. ${ }^{1}$ Health care facilities routinely require TB testing for employees and volunteers. Universities and

Corresponding Author: Kimberly McKeirnan, Washington State University, PO Box 1495, Spokane, WA 99210-1495. Tel: 509- 358-7720. E-mail: Kimberly.McKeirnan@wsu.edu trade programs for health-related fields require TB testing of enrolled individuals. Additionally, residents of longterm care facilities are at an increased risk for TB transmission, resulting in the need for skilled healthcare practitioners to screen residents. ${ }^{3}$

The Mantoux tuberculin skin test (TST) has historically been the standard method of screening for tuberculosis. ${ }^{4}$ However, newer tuberculosis detection tests have grown in this niche. ${ }^{4}$ A modernized method for detecting tuberculosis is interferon-gamma release assays (IGRAs). ${ }^{5}$ Some advantages of this test include a single patient visit versus two, results within 24 hours, and zero false positives. ${ }^{5}$ Disadvantages include invasive collection method (blood draw), high cost relative to the Mantoux TST, limited data in specific patient populations, and an eight- to 30hour window to test blood samples because of limited white blood cell viability. ${ }^{5}$

Screening efforts conducted by pharmacists for detection of TB have been used since $2006 .{ }^{6}$ A successful 


\section{American Journal of Pharmaceutical Education 2019; 83 (4) Article 6622.}

screening program has been implemented in a community pharmacy using the Mantoux test as described by Jakeman and colleagues. ${ }^{6}$ Pharmacists in Idaho and New Mexico are allowed to prescribe TB screenings autonomously, while many other states allow pharmacists to perform a TST through a collaborative drug therapy agreement (CDTA). ${ }^{7}$ Pharmacists are ideal health care providers to perform TB skin tests because pharmacies are in close proximity to patients in the community and provide convenient access with extended hours of operation. ${ }^{8}$ Pharmacists have also demonstrated high rates of follow-up for the reading of the test, reported to be $92.8 \%$ to $94.4 \%{ }^{6,9}$

To assist pharmacists in expanding their clinical skillset to include TST, the Washington State Pharmacy Association (WSPA) and Washington State Department of Health Tuberculosis Program developed the Tuberculin Skin Testing Certificate program for administration of the Mantoux tuberculin skin test. ${ }^{10}$ While certification is not required in Washington State to perform a TST, the program was developed to help pharmacists refine skills and develop confidence in performing the test. The training includes the following components: viewing a preclass video, participating in a live, hands-on practicum with instruction on the two-step process for the Mantoux TST, and completing live skills assessment to ensure competency. ${ }^{10}$ The video component includes a narrated presentation informing learners of TB fundamentals including high-risk populations, test placement, assessment of test results, and the referral process for positive tests. Included in the live training are pharmacy-specific points, such as using a prescriptive protocol, and referring patients for follow up. During the live practicum, attendees practice the intradermal saline injection technique on a peer and are assessed on ability to interpret TST results using artificial demonstration arms.

The faculty and staff members at the Washington State University (WSU) College of Pharmacy believed that teaching student pharmacists how to provide TST works toward the college's vision to improve public health through prevention and treatment. ${ }^{11}$ The TST content was also aligned with the Accreditation Council for Pharmacy Education (ACPE) standards 2016 for Health and Wellness, Population-based Care, Communication, and Patient Centered Care through teaching students disease prevention and detection, patient interaction and counseling skills, and the importance of placing the patient at the center of clinical decision-making. The Joint Commission for Pharmacy Practitioners (JCPP) Pharmacist Patient Care Process components were also incorporated into the development of the training to ensure a patient-centered approach. ${ }^{13}$
The TST training was incorporated into the Applied Patient Care (APC) laboratory course by adopting established TST teaching methods previously described by McKennon and colleagues. ${ }^{14}$ Different from McKennon's lecture-based approach, the laboratory-based method at WSU used team-based learning (TBL). Teaching TST through TBL has not been previously described. TBL is a three-phase process: individual preparation, the phase where students become familiar with foundational knowledge; readiness assurance, which involves completion of an individual readiness assurance test (iRAT) and a team readiness assurance test (tRAT) to incentivize the students to engage with the material prior to coming to class; and application of key concepts, which involves application exercises used to help students engage with the material on a deeper and more meaningful level. ${ }^{15}$ Implementing TBL requires the adoption of different teaching and learning methods for both students and instructors. ${ }^{15}$ Four key principles of learning are established in a TBL environment: carefully formed teams, accountability for individual and team work, frequent and timely feedback from faculty members, and team application exercises that promote learning and team development. ${ }^{15}$ Providing a TBL environment enhances students' engagement, critical-thinking abilities, and communication of content. ${ }^{15}$

There were two specific objectives for the project described in this paper. The first was to describe the implementation of a TST training program using a team-based learning model integrated into a laboratorybased course. The second objective was to evaluate the student pharmacists' achievement of the learning objectives as well as students' subjective perception of the activity's impact on their confidence, understanding of content, ability to communicate, and interest in offering TST services in future practice.

\section{METHODS}

At WSPA, training in TST was incorporated into the APC laboratory, a required course for the second-year (PY2) student pharmacists at WSU. The cohort for the 2016-2017 academic year consisted of 120 student pharmacists. The APC course met weekly during the fall semester and included a one-hour tutorial and two-hour laboratory session, with one week allotted to complete the TST content. The team of instructors for the TST session included the course instructor, the WSPA's TST trainer and developer, one student completing an advanced pharmacy practice experience (APPE), and one academic fellow. Two laboratory classrooms were used for the training.

To encourage students to engage with course material prior to class, the TBL pedagogical approach was 


\section{American Journal of Pharmaceutical Education 2019; 83 (4) Article 6622.}

applied to this laboratory session. The WSPA TST training program was easily implemented with a TBL approach because the training already included necessary components for a TBL format. The online preclass material was used for individual preparation, the knowledge assessment was adopted for readiness assurance, and the live training portion was used for the application of key concepts. ${ }^{10}$ By following the TBL readiness assurance process, instructors provided immediate feedback to the learners regarding knowledge gaps or misconceptions. ${ }^{16}$ When designing the laboratory session, faculty members incorporated the four essential principles of TBL: groups of four to six learners were properly formed at the start of the semester and maintained throughout; students were held accountable for their individual and team work via readiness assurance quizzes and application of key concepts evaluations; students were provided feedback in a timely manner through use of the Immediate Feedback Assessment Technique (IF-AT) scratch sheets during readiness assurance; and the assignments were designed to promote learning and team development. ${ }^{17}$

Educational components of the laboratory session were designed to meet Bloom's Taxonomy levels of knowledge and application and to integrate Fink's Taxonomy elements of foundational knowledge, application, and human dimension. ${ }^{18,19}$ Pedagogical mapping for TBL is outlined in Table 1. Learning objectives for the TST training included the following: demonstrate proficiency in the ability to administer a tuberculin skin test; describe the process of and demonstrate competency in interpreting a tuberculin skin test; describe what to do if a test is positive including reporting the infection and counseling the patient; and evaluate and identify criteria indicating when a second tuberculin skin test is necessary. Achieving competency for all learning objectives was the required outcome for the students participating in the laboratory session.

As part of their individual preparation, all students were required to watch the WSPA's online video tutorial on TST prior to class. ${ }^{10}$ Access to material was posted on the Blackboard Learning Management System (Blackboard Inc, Washington, DC) five days before class, giving students time to become familiar with the material prior to the iRAT, tRAT, and laboratory session.

Assessment of student learning included multiple components. The iRAT and tRAT assessed student knowledge of foundational material while the TST skills were assessed during the laboratory session. The iRAT and tRAT were administered during the one-hour tutorial with the goals of encouraging student pharmacists to engage with the material prior to the live portion of the training and to enhance communication skills within the

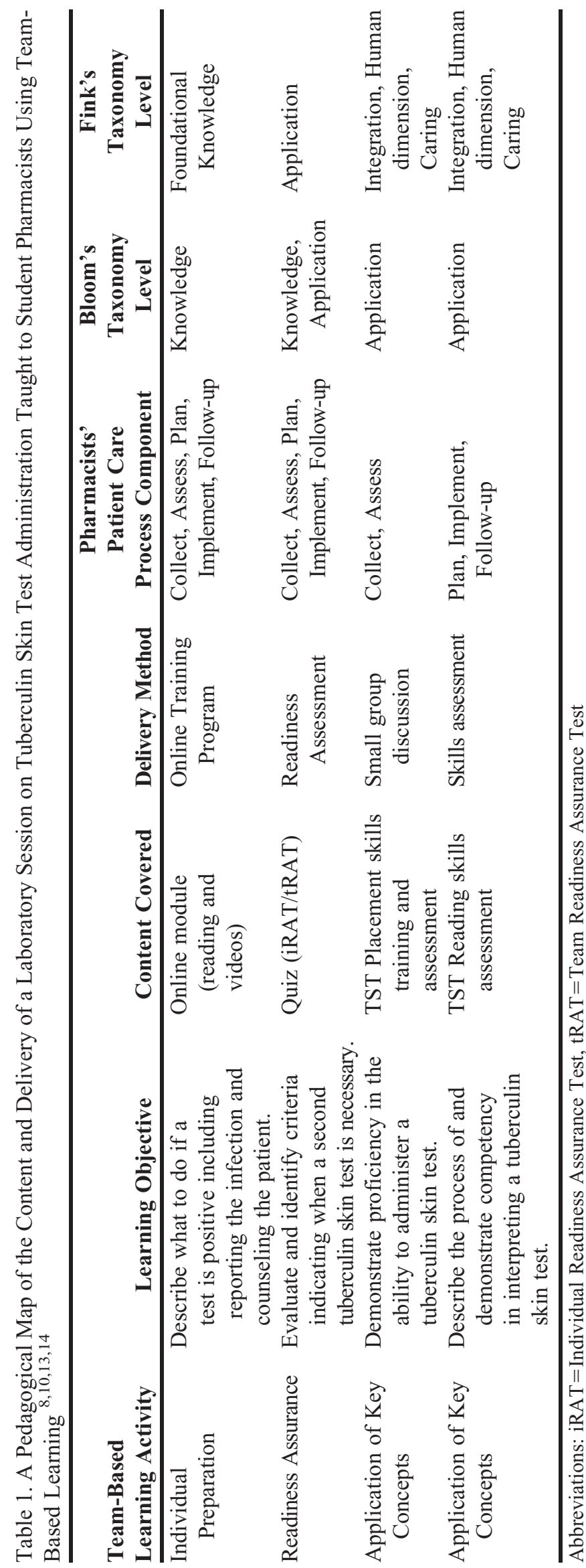




\section{American Journal of Pharmaceutical Education 2019; 83 (4) Article 6622.}

teams. The iRAT assessment was administered via a 10minute quiz consisting of 10 multiple-choice questions posted to ExamSoft (ExamSoft Worldwide, Inc, Dallas, TX). Notes and other resources were not allowed during the assessment. After completing the iRAT, students completed the tRAT in teams of four to six. Teams were created alphabetically and assigned by the instructor at the beginning of the semester. The tRAT was untimed but took approximately 15 minutes to complete. The tRAT was administered using a paper copy of the quiz and an IF-AT scratch sheet, allowing for immediate feedback. Teams were awarded $100 \%$ credit if the correct response was chosen on the first attempt and 50\% credit if the correct response was selected on the second attempt. Quantitative statistics (averages) were used to assess quiz scores.

The Application of Key Concepts took place during the laboratory session. Two teams were combined to form a group of eight to 12 students. Each team was assigned a 20-minute timeslot for TST placement instruction and technique assessment. An additional 20 minutes was used to assess TST reading and evaluation of results. For TST placement training, students were instructed in the fundamentals of intradermal injections and then required to demonstrate competency by placing a saline test on a partner while an instructor coached and observed. Using a ruler, the instructor evaluated whether the student achieved a $6 \mathrm{~mm}$ or greater bleb on the partner's forearm. If the bleb did not appear, was too small, or there was an obvious error in technique (eg, incorrect injection depth, did not follow bloodborne pathogen procedures), the evaluator would provide guidance and then reassess the student's technique. This assessment was graded as pass/ remediate, and students were allowed multiple attempts, if needed, to correctly demonstrate the skill.

After completing the TST placement, student pharmacists demonstrated competency in reading a TST using artificial demonstration TST arms. To meet competency on this skill, student pharmacists had to read four patient cases, measure the corresponding artificial arm skin reaction for each, and determine whether the test was positive or negative for each patient case. Ten artificial arms were used so that each student pharmacist on the team had a unique set of reactions to measure. Student pharmacists who did not meet competency on the first attempt were given additional instruction and the opportunity to remediate until competency was reached.

To assess student pharmacists' opinions on the TST training and the effectiveness of TBL in helping students achieve the course learning objectives, a TST Learning Opinion Survey was developed that consisted of 10 Likert-scale questions (Table 2). The questions were developed to assess the student pharmacists' self-perceived achievement of the class learning objectives (questions 14), opinions about the TBL experience (questions 5-8), and interest in making TST a part of their future pharmacy practice (questions 9 and 10). Questions were developed from reviewing previous surveys used to assess student perceptions of TBL, a previous TST training program, and other training programs involving clinical services in a community pharmacyhttps://www.ncbi.nlm.nih.gov/pubmed/? term $=$ Camiel $\% 20 \mathrm{LD} \% 5 \mathrm{BAuthor} \% 5 \mathrm{D} \&$ cauthor $=$ true $\&$ cauthor_uid $=27293234 .{ }^{14,20-23}$ The survey questions were peer reviewed by one faculty member, one resident, and one APPE student, all of whom were not involved in the initial question development. The survey instrument was posted on the Blackboard Learning Management System (LMS) and available only during the week of content delivery with the intention that results would reflect the students' perceptions immediately after completing the training. To promote survey completion, student pharmacists were asked to complete the survey on laptops made available for this purpose at the conclusion of the laboratory session. Students were informed that survey participation was voluntary, individual responses would be de-identified prior to aggregate analysis, and that participation in the survey would have no impact on their grade for either the laboratory session or the course. Student identification numbers were recorded at the time the survey was administered to detect survey completion but were removed prior to aggregate analysis.

An additional method of gauging student interest in TST was based on an analysis of the number of student pharmacists who chose to pay for the optional WSPA TST Certificate. ${ }^{10}$ Students were required to complete the WSPA content as part of the course, but had the option of paying for the WSPA certificate of completion. The cost was $\$ 25$ for WSPA student members and $\$ 35$ for nonmembers. The WSU Office of Research Assurances reviewed this protocol and found the project to be exempt from institutional review board approval.

\section{RESULTS}

Multiple methods of evaluation were used for the TST laboratory session. The iRAT and tRAT scores, along with the live TST placement and reading assessment competency ratings were compiled to determine student pharmacist knowledge of TST content. Mean scores on the iRAT and tRAT were $84 \%(\mathrm{SD}=15 \%)$ and $96 \%(\mathrm{SD}=6 \%)$ respectively. The IRAT and tRAT results are displayed in Figure 1. All 120 student pharmacists achieved competency during the skills evaluation of the TST placement and interpretation. Although most met competency requirements on the first attempt, some required a second and third attempt. Out of 120 students, 59 $(49 \%)$ chose to pay for the WSPA Certificate. 


\section{American Journal of Pharmaceutical Education 2019; 83 (4) Article 6622.}

Table 2. Results of an Opinion Survey Administered to Student Pharmacists After Completing a Laboratory Session on Tuberculin Skin Test Administration Results of TST Learning Opinion Survey $(\mathrm{n}=113)$

\begin{tabular}{|c|c|c|c|c|c|c|}
\hline & $\begin{array}{c}\text { Strongly } \\
\text { Agree }\end{array}$ & Agree & Neutral & Disagree & $\begin{array}{l}\text { Strongly } \\
\text { Disagree }\end{array}$ & Omit \\
\hline \multicolumn{7}{|l|}{$\begin{array}{l}\text { Student Perceptions of Learning Objective Achievement } \\
\text { (Questions 1-4) }\end{array}$} \\
\hline \multicolumn{7}{|l|}{ The ability to collaborate with my team helped me: } \\
\hline $\begin{array}{l}\text { Demonstrate proficiency in the ability to administer a tuberculin } \\
\text { skin test. }\end{array}$ & 66 & 42 & 4 & 0 & 1 & 0 \\
\hline $\begin{array}{l}\text { Describe the process of and demonstrate competency in } \\
\text { interpreting a tuberculin skin test. }\end{array}$ & 70 & 39 & 5 & 0 & 1 & 1 \\
\hline $\begin{array}{l}\text { Describe what to do if a test is positive including reporting the } \\
\text { infection and counseling the patient. }\end{array}$ & 63 & 39 & 8 & 1 & 1 & 1 \\
\hline $\begin{array}{l}\text { Evaluate and identify criteria indicating when a second } \\
\text { tuberculin skin test is necessary. }\end{array}$ & 62 & 39 & 9 & 2 & 1 & 0 \\
\hline \multicolumn{7}{|l|}{ Student Perceptions of Team-Based Learning (Questions 5-8) } \\
\hline $\begin{array}{l}\text { The ability to collaborate with my team improved my knowledge } \\
\text { of TST prelab material. }\end{array}$ & 61 & 40 & 10 & 0 & 1 & 1 \\
\hline $\begin{array}{l}\text { Problem-solving with my team enhanced my ability to apply } \\
\text { my TST knowledge. }\end{array}$ & 57 & 43 & 9 & 3 & 1 & 0 \\
\hline $\begin{array}{l}\text { Interacting with a teammate helped build my confidence in } \\
\text { practicing TST placement. }\end{array}$ & 77 & 32 & 2 & 1 & 1 & 0 \\
\hline Working with my peers improved my communication skills. & 60 & 40 & 11 & 0 & 1 & 1 \\
\hline \multicolumn{7}{|l|}{ Student Opinions on TST in Future Practice (Questions 9-10) } \\
\hline $\begin{array}{l}\text { Incorporating TST in my future pharmacy practice is something } \\
\text { that I am interested in pursuing. }\end{array}$ & 50 & 43 & 13 & 5 & 1 & 2 \\
\hline $\begin{array}{l}\text { I believe that my future pharmacy practice will support } \\
\text { implementing TST. }\end{array}$ & 54 & 41 & 11 & 4 & 3 & 0 \\
\hline
\end{tabular}

TST $=$ Tuberculin Skin Test

Results of the TST Learning Opinion Survey are reported in Table 2. Ninety-four percent (113) of student pharmacists completed the survey. Overwhelmingly, student pharmacists reported that they believed TBL aided in their learning. The majority of the 113 respondents either agreed or strongly agreed with survey questions regarding the use of TBL in student ability to demonstrate proficiency in TST administration (108, 95.6\%), demonstrate competency in TST interpretation $(109,96.5 \%)$, describe the process for reporting a positive test and appropriate patient counseling $(102,90.3 \%)$, and indicate when a second TST is necessary $(101,89.4 \%)$. The open-ended student feedback also indicated a positive view of the curricular delivery model. One respondent wrote, "overall, the TST training was well organized and well executed. I would much rather have the TST training done as it was rather than in a traditional classroom environment." Many $(23 \%)$ students also specifically mentioned that the artificial demonstration TST arms, with wheel size variation, were extremely helpful in learning to interpret the test.

A majority of the 113 student pharmacists either agreed or strongly agreed, and in some cases openly com- mented in the responses to questions 5, 6, 7, and 8, that collaborating with the team improved their knowledge of the pre-laboratory material $(101,89.4 \%)$. Survey respondents also indicated that interaction during TBL improved their knowledge $(100,88.5 \%)$, confidence $(109,96.5 \%)$, and communication skills $(100,88.5)$. In the comments section, one respondent stated, "I really enjoyed the set up of this class. I liked learning with my peers and walking through the steps with my teammates supplemented my knowledge. It was a great opportunity to learn TB testing." Other respondents mentioned feeling confident in their ability to properly administer the test and interpret the results. Comments regarding willingness and interest in implementing TST at a future pharmacy were also noted. Working in a team aided in their ability to counsel a patient with a positive test result and to determine if a second screening would be necessary in the event of a false positive.

The researchers also wanted to evaluate student interest in implementing TST services in their future pharmacy practice. Ninety-three respondents $(82.3 \%)$ agreed or strongly agreed that incorporating TST in future practice was of interest to them, and 95 respondents $(84.1 \%)$ 


\section{American Journal of Pharmaceutical Education 2019; 83 (4) Article 6622.}

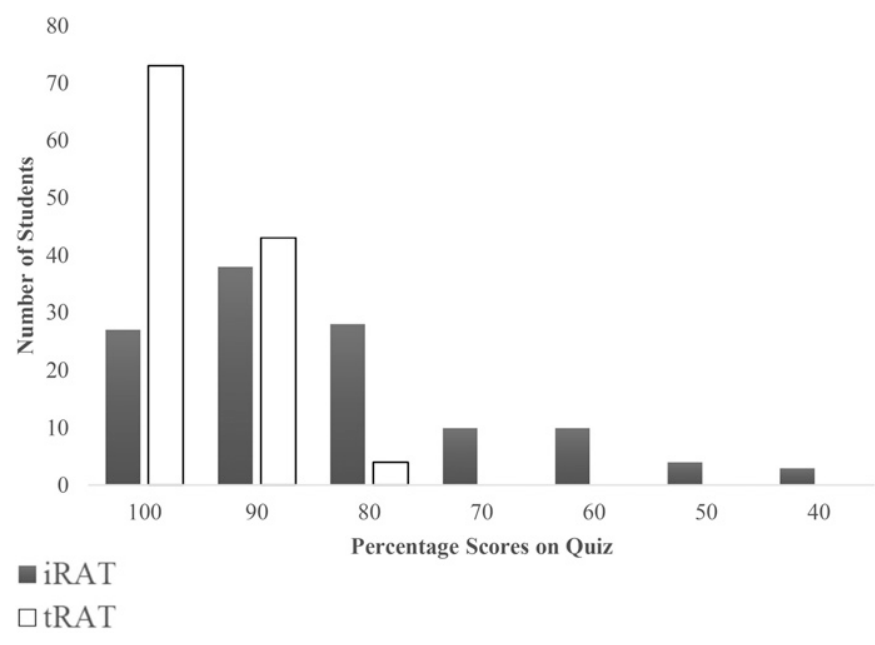

Figure 1. Student iRAT and tRAT Scores by Percentage

Abbreviations: $\mathrm{iRAT}=$ Individual Readiness Assurance Test, tRAT $=$ Team Readiness Assurance Test

believed their future pharmacy practice would support implementing TST. One student stated, "I'm glad we were able to get this certification and teaching. I feel this will go a long way in the field of pharmacy, especially when provider status is implemented."

\section{DISCUSSION}

Team-based learning is an effective classroom teaching method and has been used extensively in laboratory-based courses. ${ }^{16,20}$ As many institutions transition from a lecture-based model to an active-learning or "flipped" model, TBL is a valuable technique that can be used to teach content and interactive skills application. Research conducted in this project supported the hypothesis that student pharmacists can effectively learn TST through TBL. The majority of respondents (91\%) agreed or strongly agreed that TBL helped them meet the TST training learning objectives. The respondents believed that by working in teams, they had greater knowledge of the individual preparation material and that peer work in a TBL environment improved their communication skills.

Using the TBL model allowed us to train 120 student pharmacists in less than three contact hours and could likely be used to train even larger student groups. This activity could be replicated at other colleges, which would expand the number of student pharmacists who are confident in their ability to provide TST services. Student pharmacists involved in this research stated that they appreciated the opportunity to learn TST, recognizing that the service would likely be offered in their future practice. As pharmacists continue to advance pharmacy practice by providing clinical services, pharmacy programs need to include education in providing innovative pharmacy services in the curriculum.
While not all states allow pharmacists to perform this type of clinical service, all student pharmacists can benefit from knowledge of tuberculosis as a disease state, TST as a screening tool, and the referral process for a positive test. Ultimately, pharmacists are well qualified and equipped to fill this healthcare need. ${ }^{6,7}$ If pharmacists nationwide were trained to provide TST, access to this important health screening could be meaningfully increased. According to the $\mathrm{CDC}$, maintaining similar rates of $\mathrm{TB}$ detection and treatment in the future will not achieve TB elimination in the United States. More programs to identify and treat active TB disease are needed. ${ }^{24}$ Exposing student pharmacists to this skillset can certainly strengthen TB elimination efforts.

Through this project, opportunities for improvement were identified, and course instructors have plans to modify this activity for future cohorts. One challenge of implementation has been time. The current pharmacy class size at WSU is 120 students. However, class sizes are expected to increase, which would limit the instructor's ability to interact with and assess students in small groups. In order to improve the flow of the assessment process without compromising quality, the instructors plan to develop a standardized TST placement rubric. The rubric will reduce variation among graders, allowing other faculty members who are experienced evaluators of hands-on patient care laboratory skills but not necessarily TST content experts to assist with grading. For this study, a content-expert from the WSPA traveled to WSU to assist in laboratory discussion and student assessment. A standard rubric for grading would increase the sustainability of the program, allowing it to continue even if a WSPA expert is not available. Additionally, a rubric would reduce the implementation workload for other programs nationwide that would like to adopt the training model but do not have a content expert readily available to assist with training.

There are limitations to the methods of this research. Student pharmacists' baseline knowledge of TST was not evaluated prior to completing the laboratory session. However, information on TB had not been previously covered in the curriculum. While the survey developed by the researchers was created from previously published work and was peer-reviewed, it was not validated in its current form before use. Additionally, students were required to include their student identification (ID) number in the survey response to ensure an accurate response rate. All ID numbers were removed during data exportation from Blackboard prior to data analysis. However, student knowledge that their ID number was recorded may have led to biased responses on the survey. Lastly, because all students were required to participate in the TBL approach, 


\section{American Journal of Pharmaceutical Education 2019; 83 (4) Article 6622.}

there was no control group for comparison. Even though McKennon and colleagues used a non-TBL approach, the content delivery and assessment were different enough that direct comparison of their results with those of our study was not possible.

\section{CONCLUSION}

Through this innovative model, student pharmacists met the TST learning objectives and developed knowledge and confidence. In less than three contact hours, student pharmacists were successfully trained to place and interpret a tuberculin skin test. As pharmacists continue to expand into more clinical roles, training in TST is an opportunity to diversify a pharmacist's skill set and to increase access to an important public health service.

\section{REFERENCES}

1. Questions and answers about tuberculosis. Centers for Disease Control and Prevention. https://www.cdc.gov/tb/publications/faqs/ pdfs/qa.pdf. Accessed May 20, 2017.

2. Pitchenik AE, Fertel D, Bloch AB. Mycobacterial disease: epidemiology, diagnosis, treatment, and prevention. Clin Chest Med. 1988;9:425-441.

3. TB risk factors. Centers for Disease Control and Prevention. https:// www.cdc.gov/tb/topic/basics/risk.htm. Accessed May 20, 2017. 4. Tuberculin Skin Testing. Centers for Disease Control and Prevention. https://www.cdc.gov/tb/publications/factsheets/testing/ skintesting.htm. Accessed August 11, 2017.

5. Interferon-Gamma Release Assays (IGRAs) - Blood Tests for TB Infection. Centers for Disease Control and Prevention. https:// www.cdc.gov/tb/publications/factsheets/testing/igra.htm. Accessed August 11, 2017.

6. Jakeman B, Gross B, Fortune D, et al. Evaluation of a pharmacistperformed tuberculosis testing initiative in New Mexico.J Am Pharm Assoc. 2015;55(3):307-312.

7. Atkinson D, Dering-Anderson AM, Adams A. Pharmacy-based tuberculosis skin testing (TST): approaches to legal authority. Inov Pharm. 2017;8(2): Article 13.

8. Re: health care workshop, Project No. P131207. National Association of Chain Drug Stores. http://www.nacds.org/ceo/2014/ 0508/supplemental_comments.pdf. Accessed May 20, 2017.

9. Glaze LE, Rowe SL. Pharmacists' role in tuberculosis: prevention, screening, and treatment. J Am Pharm Assoc. 2015;55(2):118-120.

10. Washington State Pharmacy Association. Tuberculin skin testing certificate. http://www.wsparx.org/default.asp?page=tuberculincert. Accessed June 12, 2017.
11. College mission and vision statement. Washington State University College of Pharmacy. https://www.pharmacy.wsu.edu/ facultystaff/files/college_mission-vision2014.pdf. Accessed June 12, 2017.

12. Accreditation Council for Pharmacy Education. Accreditation standards and key elements for the professional program in pharmacy leading to the doctor of pharmacy degree. Standards 2016. https:// www.acpe-accredit.org/pdf/Standards2016FINAL.pdf. Accessed May 20, 2017.

13. Joint Commission of Pharmacy Practitioners. Pharmacists' patient care process. May 29, 2014. http:/www.pharmacist.com/ sites/default/files/PatientCareProcess.pdf. Accessed May 20, 2017. 14. McKennon SA, Arnold J. Student pharmacists as tuberculosis screeners. Am J Pharm Educ. 2016;80(2):Article 24. doi:10.5688/ ajpe 80224 .

15. Ofstad W, Brunner LJ. Team-based learning in pharmacy education. Am J Pharm Educ. 2013;77(4):Article 70.

16. Farland MZ, Sicat BL, Franks AS, Pater KS, Medina MS, Persky AM. Best practices for implementing team-based learning in pharmacy education. Am J Pharm Educ. 2013;77(8):Article 177. doi:10.5688/ajpe 778177 .

17. Johnson C. Team-based learning for health professions education: a guide to using small groups for improving learning. $J$ Chiropr Educ. 2009;23(1):47-48.

18. Bloom BS. Taxonomy of Educational Objectives, Handbook I: The Cognitive Domain. New York, NY: McKay; 1956.

19. Fink LD. Creating Significant Learning Experiences. An Integrated Approach to Designing College Courses. San Francisco, CA: Jossey-Bass, 2003.

20. Huitt TW, Killins A, Brooks WS. Team-based learning in the gross anatomy laboratory improves academic performance and students' attitudes toward teamwork. Anat Sci Educ. 2015;8(2):95103. doi: 10.1002 /ase. 1460 .

21. Frame TR, Cailor SM, Gryka RJ, Chen AM, Kiersma ME, Sheppard L. Student perceptions of team-based learning vs traditional lecture-based learning. Am J Pharm Educ. 2015;79(4):Article 51. doi: 10.5688/ajpe79451.

22. Camiel LD, Mistry A, Schnee D, et al. Students' attitudes, academic performance and preferences for content delivery in a very large self-care course redesign. Am J Pharm Educ. 2016;80(4):Article 67. doi: 10.5688/ajpe80467.

23. McKeirnan KC, Akers JM, Czapinski JC, Robinson JD. Using collaborative drug therapy agreements to train student pharmacists to provide clinical patient care services. Am J Pharm Educ.

2017;81(2):Article 31. doi:10.5688/ajpe81231.

24. Schmit KM, Wansaula Z, Pratt R, Price SF, Langer AJ. Tuberculosis - United States, 2016. MMWR Morb Mortal Wkly Rep. 2017;66:289-294. https://www.cdc.gov/mmwr/volumes/66/wr/ mm6611a2.htm. 